\title{
National-cultural veil of etiquette phrases and environmentally responsible behavior
}

\author{
Olga Nikolenko ${ }^{1, *}$ \\ ${ }^{1}$ Don State Technical University, Gagarin Square, 1. Rostov-on-Don, 344003, Russia
}

\begin{abstract}
The article sets the goal, by direct observation of the facts of the language, to get ahead of how the language encodes images that are formed under the influence of cultural knowledge in the thoughts of a particular person, conveys the subtle nuances of the picture of the world and affects the non-verbal behavior of its carrier. The author believes that it is possible to understand the complex mechanism of communication by referring to linguistic and cultural studies, theory and history of culture, ethnography, psychology and other humanitarian disciplines, which contribute to a comprehensive description of language and culture, thereby laying the psycholinguistic and national-cultural foundations for the correct interpretation of the reproduced and received information. This presupposes, among other things, the awareness of the addressee of the speech that the addressee's interest in the information he receives is awakened not only by the content of the utterance, but also in the external form of its presentation, which includes phonetic framing, lexical selectivity, intonation design, structural length, qualifying as accompanying elements to the meaning of the statement. The author comes to the conclusion that etiquette forms of communication are capable of performing any of the linguistic functions, including suggestive, which lays a certain imprint on the very act of communication, giving it some subtext characteristic and contributing to the formation of a given decoration in the minds of the recipients of the dialogue.
\end{abstract}

\section{Introduction}

Modern linguistic science increasingly tends to study the communicative personali-ty in the context of national culture and taking into account the speech self-embodiment, i.e. examines language through the prism of a person's speech behavior in a particular nationalcultural environment, describes the specifics of a speech act, identifies factors that affect the process of communication in a specific society with a specific interlocutor. Naturally, in order to avoid communicative failures both in intercultural and interpersonal communication, the parties entering into a verbal (or non-verbal) dialogue should not only know the specific individual and / or national characteristics of their interlocutor, captured in culture, everyday life , religion, people, their value orientations, but also follow them in the process of speech interaction. Tied into a single whole, units of verbal and non-verbal etiquette ultimately convey homogeneous content and equally carry information about the relationship between

* Corresponding author: olganikolenko15011977@gmail.com 
communicants and the distribution of personal "powers" in them, which makes it possible to combine verbal linguistic units with non-verbal syntaxemes in the com-munication process. Intuitively (or deliberately) trying to improve his lexical and semantic base in the process of communication, a person subconsciously refers to the spiritual and cultural heritage of his people, transfers his experience to modern reality. This allows us to assume that etiquette forms of communication, being cross-cultural, serve as a conceptual and terminological toolkit that brings the communication pro-cess to the desired level. Being marked signs of the communication process, they also give personal characteristics: they reveal the inner world of the communicants, correct their consciousness.

\section{Materials and methods}

The fundamental within the framework of the proposed research are descriptive and discursive methods, including the technique of observation, interpretation, comparison and generalization, which make it possible to describe the specific features of the language as a whole, as well as the synchronization and diachronization of the analysis of linguistic and cultural-historical facts. The methods of comparative and logical analysis, systematization of empirical and theoretical data are used as general scientific research methods

\section{Results}

A person absorbs universal national codes of communication from birth in a family, in preschool and school institutions, in a micro-society, and learns at the level of intuition. However, there are those that he learns about directly in speech contact.

The differences in linguistic and behavioral formulas are most clearly manifested in etiquette, which is understood as the rules of speech behavior in a particular situation and in a particular society, established in accordance with the tradition of a particular people.

Indeed, it is language as a priority means of communication, as a tool for storing and transmitting information that is a kind of mirror that reflects the rich culture of any nation and directs a person into a specific linguistic channel. And since the signs of the language act as a kind of code for the transmission of the real and the desired, we replicate our ideas about the world in visual mental images through the word, forming a chain of links "image concept". In other words, any (even figurative) information corresponds to a linguistic embodiment, caused by a wide variety of associations due to acquired or intuitive knowledge, thanks to which a person draws "pictures", perceives them, and then forms an attitude towards their inner fulfillment.

In this regard, the question of what information about the language and its functions must be possessed is open to many in order for it to become a real means of communication, and not a stumbling block in the process of speech interaction at all its stages. By entering into communication, we in one way or another comply with its structural laws. Let us present in the table the main stages of speech interaction and define their functions.

Let's take a closer look at the meaningful table plan.

The success of communication at the initial stage, of course, is associated with the choice of forms of address; the appeal is of great importance in the "emergence" of contact between the interlocutors, since the correct contextual use of these linguistic signs helps to emotionally influence the addressee of the utterance and form a positive image of the addressee.

So, addressing an interlocutor, equal in age, by name, patronymic, not only reflects the official character, but also to a certain extent fixes his social assessment; the choice of abbreviated and diminutive forms of the name lays down a positive interpersonal disposition towards each other of the speakers; addresses, which include evaluative and descriptive 
lexemes, encourage the speaker to express directly (more often with a positive attitude) or covertly (veiling negative) emotionality and evaluativeness.

Table 1. Stages of communication.

\begin{tabular}{|c|c|c|}
\hline $\begin{array}{c}\text { Communication } \\
\text { stage }\end{array}$ & Example & Function \\
\hline Greeting & $\begin{array}{l}\text { Hello! } \\
\text { Good afternoon (morning, } \\
\text { evening)! } \\
\text { Good day (morning, evening)! } \\
\text { Greetings! } \\
\text { Hey! }\end{array}$ & $\begin{array}{l}\text { open communication, tunes in to } \\
\text { productive communication; states } \\
\text { the situation or implicitly conveys } \\
\text { the attitude towards it }\end{array}$ \\
\hline Establishing contact & $\begin{array}{l}\text { How are you? } \\
\text { What's up? } \\
\text { How is your health? }\end{array}$ & $\begin{array}{l}\text { inspires the addressee with interest } \\
\text { in him and his life. }\end{array}$ \\
\hline $\begin{array}{l}\text { Submission of } \\
\text { information }\end{array}$ & $\begin{array}{l}\text { Do you know that ... } \\
\text { Have you heard that ... }\end{array}$ & $\begin{array}{l}\text { the first part acts as an auxiliary } \\
\text { suggestive element to the second } \\
\text { part. }\end{array}$ \\
\hline $\begin{array}{l}\text { Leaving } \\
\text { communication }\end{array}$ & $\begin{array}{l}\text { I have to go! } \\
\text { I have to go! } \\
\text { I'm in a hurry! } \\
\text { Someone is waiting for me! }\end{array}$ & $\begin{array}{l}\text { help to get away from conflict } \\
\text { moments with negative } \\
\text { communication. }\end{array}$ \\
\hline Parting & $\begin{array}{l}\text { Goodbye! } \\
\text { See you! } \\
\text { Goodbye! } \\
\text { Until! } \\
\text { Happen! }\end{array}$ & $\begin{array}{l}\text { express hope for a new meeting } \\
\text { (with positive verbal contact) or } \\
\text { convey a desire to end } \\
\text { communication (with negative } \\
\text { verbal contact). }\end{array}$ \\
\hline
\end{tabular}

Not knowing the etiquette form of greeting - not being able to communicate. By greeting a person, we, on a subconscious level, show our intention to continue communication at this particular moment, to lay the foundation for future communication, to express respect, wish good health, "infect" with a positive, etc. Therefore, every kind of greeting is situationally marked.

For example, a youth word form. "Privet!» shows that there is a relaxed relationship between the interlocutors; genius combination "Dobrogo zdorov'ya!» reflects the suggestively directed thinking of the addressee of speech; "Zdorovo!» has a rough connotation and is colloquial in nature; "Privetstvuyu vas!» usually directed towards a group of people gathered on the basis of a common interest; pronouncing «Zdravstvujte!», «Dobroe utro!», "Dobryj den'!», "Dobryj vecher!» (as opposed to genius syntaxemes «Dobrogo zdorov'ya!», "Dobrogo utra!», «Dobrogo dnya!», "Dobrogo vechera!»)the person not so much wishes the interlocutor health or good time, as states it as a fait accompli.

And here is the phrase « $S$ dobrym utrom!» has in its composition an implicitly presented (not materially expressed) verb "to wish", which sets a positive attitude for the whole day (therefore, in Russian there are no expressions "good afternoon" and "good evening").

In fact, if you open the semantic veil of any greeting, you will notice that each of them contains a special wish that sets the tone for communication.

If the greeting formulas open communication on their own, then the farewell formula is always preceded by one of the standard phrases indicating the need to end the dialogue: « $Y a$ dolzhen idti!», "Mne pora!», and then, with positive communication, they wish all the best and the best (as with a greeting) and express hope for a new meeting. If the speech interaction was negative, at the subconscious level, the person chooses the formula for the completion of communication «Proshchajte!», which, given its semantics, means asking forgiveness for 
mistakes in behavior or communication and not holding back on remembering an unpleasant act of communication.

The conversation can end with an interesting phrase for us from the point of view of semantics and grammar « Spokojnoj nochi!». It does not have the structural options of "good night" (in another context, the definition of "quiet" is used) or "good night", probably for the reason that it conveys the exceptional meaning of a wish.

The etiquette formulas used by a person reflect the level of his education and politeness, manifested in respect towards another person and helping to get away from conflict moments. So, saying "Izvinite!», "Prostite!», We smooth out the tension in interaction and get closer to the communicant. And the phrase "Ya izvinyayus'!», in our opinion, we push the interlocutor away from ourselves with just one postfix "sya", which, being formed from the pronoun "myself," turns the vector of the dialogue to the addressee, who does not need forgiveness according to the hidden semantic indicators: he removes the feeling of guilt from himself (also with the help of the "from" prefix).

The lexeme can contribute to the creation of a negative attitude between the interlocutors "Izvinyajte!», in which the imperfect form of the verb, in grammar conveying an incomplete process or repetition of actions, reflects in the background the speaker's unwillingness to correct the mistakes he has made.

The communicative task of the speaker is the leading factor in the construction of speech unity, materially realized through specific circumstances and events [4], unfolding within the communication situation; knowledge and information that the interlocutors transmit both in the process of communication and before it through certain communication channels and with the help of stable phrases.

To achieve their communicative goal, the participants in the dialogue intuitively or intentionally choose a certain psychophysical mechanism for manifesting the meaning of a local phrase, thereby establishing certain psycholinguistic threads with each other. We believe that these mechanisms include the extralinguistic parameters of the utterance (pauses, discontinuities in speech, timbre modulation, pitch, strength of emphatic stress, etc.), which in the designated thematic space of research represent a kind of background that makes the imagination work in full swing, generate emotional experiences or update old ones. For example, lowering the tone at the end of an expression. " $S$ dobroe utrom!» makes the main diametrically opposite meaning:

Togda s dobrym utrom! Podhodim, razbiraem instrumenty (Gil MacWert).

In this example, syntactic emphasis is "superimposed" on the etiquette form, which, materializing the principle of structural expansion and acting as a pragmatic rematizer, changes the content of the sentence.

It should be remembered that emphatic intonation has a complex rhythmic pattern, a bright timbre scale and point stress:

Vecher dobryj! - wish and / or statement of fact;

Vecher / dobryj! - of the many unpleasant facts, he singles out only one as positive.

The influencing side of etiquette forms is especially powerfully represented in the media. Let's remember the first phrase of Mikhail Leontiev "Odnako, zdravstvujte!». Putting a comma after the word "however" is a written indicator that the statement contains veiled information (in spite of everything, I greet you), which proves that in the arsenal of emphatically presented etiquette forms there are all the means to make a certain impression on the recipient and to cause a response (projected in advance by the addressee) reaction.

As you can see, emphasizing emphasis on certain lexemes, emphasis reflects the speaker's communicative attitude to emphasize the supporting semantic components of the phrase [10]. She is able to strengthen the personal principle of speech, remove its impersonality and fill it with concretization. In this regard, we can say that the author's "I" and his subjective intentions are a certain indicator of the expressiveness of etiquette forms. 
All of the above explains the needs of society to consider language not only as a tool for understanding the world, transmitting information about it, but also as a means of influencing the linguistic consciousness of a particular person, his behavior, thinking and spiritual activity [9].

Lexemes that are structurally unrelated to them can actualize etiquette forms:

Vot tebe i dobroe utro! In this example, the actualization of the content occurs due to a semantic shift, which serves as a cognitive tool and reflects situational and historical realities, but this is what I think allows the creator of the utterance to remove the semantic veils and convey significant shades of meaning to the interlocutor.

Consequently, etiquette forms also act as an expressive resource, the effect of which is achieved by segmentation of a simple syntactic unit, and the concept becomes actualized only if it is localized in speech.

\section{Discussion}

The problem of examining the verbal and non-verbal behavior of a person through the prism of the national and cultural characteristics of the language began to attract the attention of scientists on a large scale since the end of the last century. One of the first Russian researchers of this area of knowledge was N.G. Komlev, who suggested that many lexemes, in addition to the main one, have a cultural-historical (background) meaning that affects the content plan of the entire lexical-semantic structure. His thought was continued by E.M. E. Vereshchagin and V. Kostomarov [1], E. Borisova [2], having proved in their works that the expansion of lexical semantics is associated with the accumulative function of the language that stores knowledge about the surrounding reality. Following them, N. Chater, M. Stewart M. Cauley, H. Morten [3], discussing the national-cultural characteristics of speech behavior, speak of the existence of national meanings in linguistic signs that form the direction of speech and non-speech action; the works of V. Karasik, S. Polyakov et al. [6, 12] describe the extra-linguistic capacity of the word reflecting the culture served by the language, concretize the models of communicative behavior of some peoples. Later works (I. Sternin and his scientific successors) put forward the idea of the lacunarized nature of the verbal and non-verbal behavior of one people relative to another [13], which allows looking at the work of foreign researchers from a new angle (B. Strickland, M. Fisher, F. Keil, J. Knobe and others) [14], analyzing the hypothesis of linguistic relativity by E. Sapir and B. Whorf and presenting cultural differences in the use of language.

\section{Conclusion}

The study confirms the idea that etiquette forms, being semantically a multi-tiered semantic structure that has a material and meaningful shell that interprets the linguistic picture of the social environment, act as an auxiliary code for isolating an information segment from the speech flow and strengthening suggestion, and also reflect national and cultural phenomena through the linguistic prism. Speech interaction should be built not only taking into account the characteristics of the participants in the dialogue [15] (their social status, age, professional interests, etc.), but also with an emphasis on the background knowledge of the specifics of the language, culture of the people speaking this language. The correct entry into speech contact, the ability to maintain it and correctly complete it is a necessary condition for successful communication, since it is the language that forms a certain image of the world perception and allows the speaker to exhaustively describe the phenomena and processes of reality, to characterize the conditions in which these processes occur, to identify the reasons that they are called, to analyze the consequences to which they lead, as well as to convey 
thin veils of subtext on an intuitive level, thereby, to a certain extent, "implant" the selfposition, changing the consciousness of the recipient [7]. Giving thought a linguistic form, the addressee somehow endows it with subjectivity: language is a universal means of communication, and each thought is individual, and the speech individuality of the participants in the speech process has a certain effect on each other [8].

\section{References}

1. E. Vereshchagin, V. Kostomarov, Language and Culture. Linguistic and Regional Studies in Teaching Russian as a Foreign Language (Moscow State University, Moscow, 2007)

2. E. Borisova, Questions of linguistics 2, 113-121 (2011)

3. N. Chater, M. Stewart, M. Cauley, H. Morten, Journal of Memory and Language, 244254 (2016)

4. R. Downey, H. Farhady, R. Present-Thomas, M. Suzuki, Language Assessment Quarterly 5(2), 160-167 (2018) DOI: 10.1080/15434300801934744

5. G. Ferguson, C. Perez-Llantada, R. Pio, A Study of Attitudes World Englishes 30, 4159 (2011) DOI: 10.1111/j.1467-971X.2010.01656.x

6. V. Karasik, Evaluative motivation, the status of an individual and verbal personality (Philologia, Krasnodar, 2014)

7. O. Nikolenko, Yu. Drozdova, L. Lepikhova, Innovative Technologies in Science and Education (2020) DOI. 10.1051/e3sconf/202021016010

8. O. Nikolenko, A. Belozerova, N. Sumina, E. Shapovalova, International Scientific Practical Conference Volgograd 673 (2018) DOI: 10.1051/shsconf/20196900081

9. O. Nikolenko, O. Zakharchuk L. Babakova, B. Morenko, The International Scientific and Practical Conference Current Issues of Linguistics and Didactics: The Interdisciplinary Approach in Humanities and Social Sciences 69, 00081 (2019) DOI:1051/shsconf/20196900081

10. O. Nikolenko, E. Shapovalova, N. Malina, International Scientific Forum «National Interest, National Identity and National Security», 269-273 (2021) DOI: 10.15405/epsbs.2021.02.02.87

11. G. Popovkina, Problems of typology of folk medicine of the Eastern Slavs, Russia 2, 8187 (2012)

12. S. Polyakov, Concepts and other constructions of consciousness (Peter, St. Petersburg 2017)

13. I. Sternin, Fundamentals of speech impact (Origins, Voronezh, 2011)

14. B. Strickland, M. Fisher, F. Keil, J. Knobe, Cognition 1, 249-261 (2014)

15. Yu. Varzonin, Language, culture and society in the humanitarian paradigm: A collection of papers (Tver, 2015)

16. V. Zinatullin, E. Chibisova, Philological sciences. Questions of theory and practice 2(4), 129-133 (2011)

17. V. Zusman, Concept in the system of humanitarian studies 2, 3-29 (2013) 